\title{
Análisis histórico y prospectiva del humedal Tierra Blanca
}

\author{
Historical analysis and prospective of Tierra Blanca wetland
}

\section{Deivy Cristhian Ruiz Sepúlveda ${ }^{1}$}

\section{Resumen}

El humedal Tierra Blanca se ubica en la Comuna Uno del municipio de Soacha Cundinamarca y, a pesar de haber sido declarado como reserva hídrica por la CAR, y de los avances en la protección de los humedales tanto a nivel global, nacional y regional, se encuentra en un estado muy avanzado de degradación, originado en los últimos 30 años por la falta de un adecuado ordenamiento territorial y la poca apropiación que tiene la comunidad sobre el espacio. Este artículo analiza los factores que han incidido en su proceso de deterioro, reflexiona sobre la forma en que el humedal fue llevado a su actual estado y propone alternativas de recuperación del área.

Palabras clave: degradación ambiental, humedal Tierra Blanca, ordenamiento territorial, Soacha.

\begin{abstract}
The Tierra Blanca wetland is located in "District One" of Soacha in the state of Cundinamarca and, despite having been declared a water reserve by the CAR, and progress in the protection of wetlands at global, national and regional levels, it is in an advanced state of degradation, caused by the lack of proper land use and limited ownership that community has had about this area in the past 30 years. This paper analyzes the factors that have influenced the process of deterioration, reflects on how the wetland was brought to its present state and proposes alternatives to recover the area.
\end{abstract}

1 Ingeniero topográfico de la Universidad Distrital Francisco José de Caldas, magister en Geografía, Programa de Estudios de Postgrado en Geografía EPG Convenio UPTC - IGAC, Colombia. deivycrs@gmail.com 
Keywords: environmental degradation, Tierra Blanca Wetland, territorial planning, Soacha. 


\section{Introducción}

El humedal Tierra Blanca se localiza en el sur del casco urbano del municipio de Soacha, Cundinamarca, en la Comuna Uno, cerca de los barrios Ducales y Compartir, entre la Autopista Sur que comunica a Bogotá con Soacha y la vía Mondoñedo que comunica a Soacha con Mosquera (ver Figura 1). Este humedal, como los demás del municipio, hace parte del grupo de los humedales de la Sabana de Bogotá y, a su vez, integra la estructura ecológica principal de Bogotá y la Sabana (Pérez, 2000).

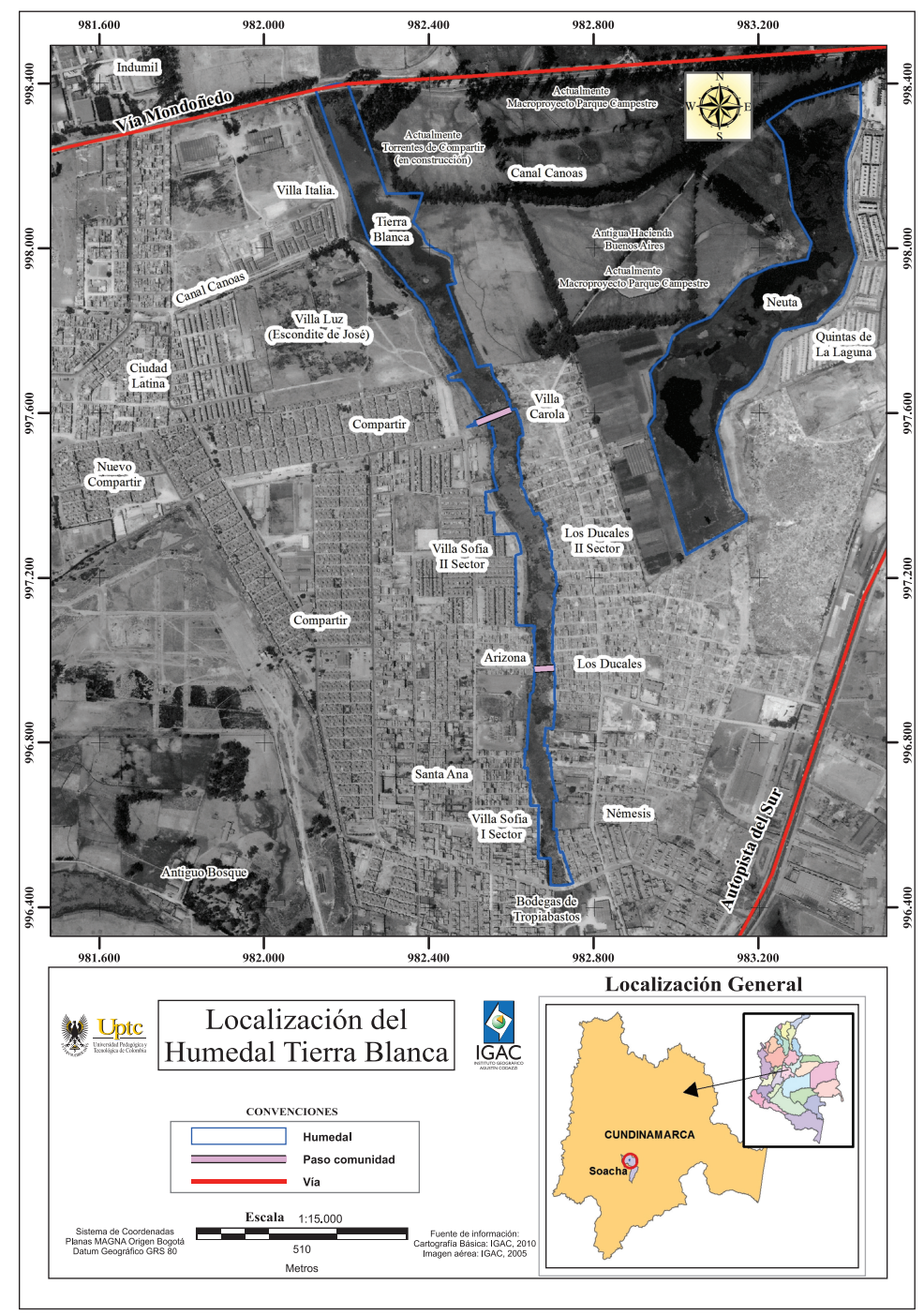

Figura 1. Mapa de la ubicación del humedal Tierra Blanca.

Fuente: Cartografía Básica, IGAC 2010 
En la Sabana de Bogotá, las áreas protegidas se encuentran en un alto grado de deterioro, originado por factores como la urbanización, la industrialización y la ocupación del espacio durante décadas (Preciado, 2005). En Soacha este proceso ha sido muy crítico, ya que el ordenamiento territorial no ha sido eficiente y ha estado filtrado por intereses de origen capitalista (Rozo, 2001), que han hecho desaparecer espacios de importancia ambiental.

Los humedales del municipio han sido afectados por el desconocimiento del territorio por parte de los actores encargados del ordenamiento territorial, quienes han influenciado procesos como la urbanización y la industrialización de los sectores ubicados en las cercanías de estos cuerpos de agua (Carvajal, 2011). Las falencias en el ordenamiento también ocasionaron que en esas zonas se establecieran personas en algún estado de vulnerabilidad, ya sea por ser víctimas del fenómeno del desplazamiento forzado o simplemente por ser pobres, lo que responde a las teorías de las injusticias espaciales y el derecho a la ciudad (Harvey, 2008; Santos, 1996; Soja, 2010). De esa forma se ha generado una mala imagen y percepción del territorio municipal por parte de la comunidad, lo que adicionalmente ocasiona la falta de apropiación y el sentido de pertenencia hacia sus espacios (H. Medellín, com. pers. 19 de julio de 2013; A. Melo, com. pers. 20 de noviembre de 2011).

Se hace necesario evidenciar como los procesos antrópicos, enlazados a las decisiones administrativas, han tenido incidencia en el humedal, a partir de los hallazgos encontrados en el lugar, los planteamientos de algunos habitantes y la bibliografía encontrada. Es indispensable recuperar el área protegida con el fin de no perder las pocas especies de fauna y flora que todavía resisten, devolverle la importancia ambiental, cultural e histórica del municipio dándolo a conocer en el territorio y así ayudar a la apropiación del espacio por parte de la comunidad y cambiar la mala imagen que se tiene del sector y el municipio.

\section{Historia de los humedales (for- mación y cambios antes de la déca- da de 1980)}

Sobre lo que ahora son la localidad de Bosa y el municipio de Soacha existió hace años un solo cuerpo de agua. Los muiscas que habitaron esta zona y brindaron especial tributo a los cuerpos de agua como humedales y lagunas (Secretaria Distrital de Ambiente de Bogotá -SDA-, 2000; Cifuentes, 2010; Correa, 2004), lo llamaron "El gran lago de Baracio" (H. Medellín, com. pers. 19 de julio de 2013). Al comenzar el periodo de la Conquista se introdujeron cambios de importancia sobre el paisaje, principalmente 
con la instauración de cultivos y ganado. "El sistema indígena de cultivo fue abandonado gradualmente y la tendencia fue drenar lo mejor posible los suelos" (Van der Hammen et al., 2008, p. 46). Esto ocasionó la fragmentación de los cuerpos de agua por el establecimiento de camellones y facilitó los asentamientos humanos (ver Figura 2).

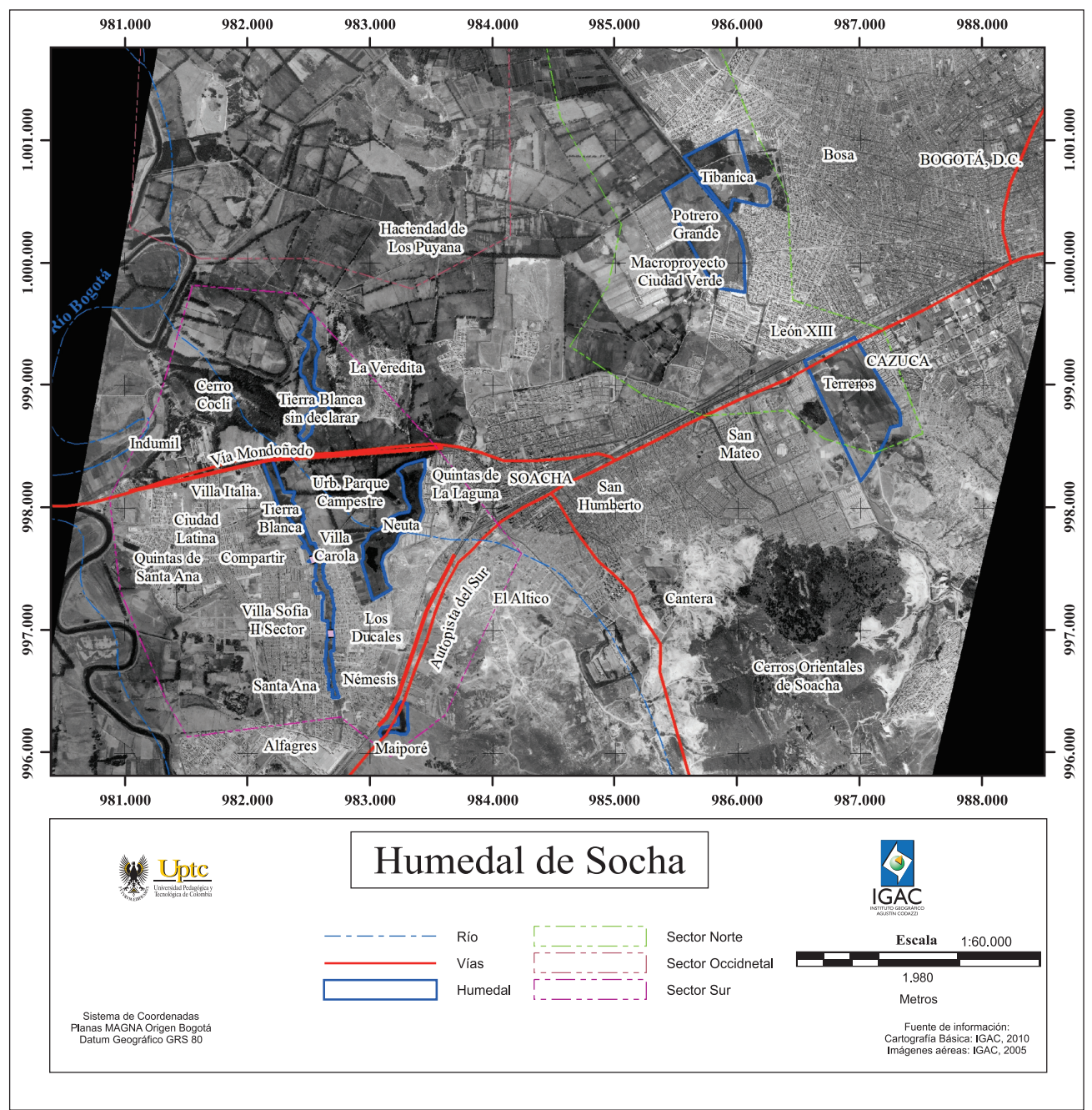

Figura 2. Fragmentación de los humedales de Soacha.

Hacia 1950, al iniciarse fenómenos como la urbanización (Montañez, 1992; Delgado, 2010; Novoa, 2010), muchos de los cuerpos de agua surgidos del primero, fueron afectados en tan alto grado que muchos desaparecie- 
ron o están a punto de desaparecer, ya que en estas áreas de importancia ambiental, se empezaron a establecer urbanizaciones de origen ilegal que generaron serios problemas y rompieron con la continuidad del paisaje (Jiménez, 2009; Preciado, 2005; Espinosa, 2009 , p. 195). De esta manera se destacan tres sectores de relevancia en el municipio con presencia de humedales (Figura 2), el sector de Tibanica, Potrero Grande y Terreros en el norte del municipio, el sector de Neuta, Tierra Blanca y Maipore en el sur; estos dos sectores se comunicaban entre sí por medio de otro grupo de humedales que se ubica en el occidente del municipio en la antigua Hacienda de los Puyana.

\section{El ordenamiento territorial y am- biental en Soacha}

En el ordenamiento territorial del municipio de Soacha existe un juego de roles en el que confluyen actores como la administración municipal, la Corporación Autónoma Regional -CAR-, los grupos organizados y el gobierno central. Desde la década del 60 del siglo pasado, y a partir del Gobierno de Pastrana, los planes de nacionales de desarrollo fueron enfocados hacia el desarrollo urbano e industrial (Moncayo, 2004), lo que hizo que en Soacha se establecieran grandes industrias, motivadas además por la cercanía con la ciudad de Bogotá (Lozada, 2000, p. 2).

Es así como hacia 1980 se realizaron los primeros proyectos de vivienda de interés social y con ello se concretó el proceso de conurbación entre el municipio y Bogotá (Moreno, 2004). Estas características hicieron que el crecimiento poblacional en Soacha se disparara, en especial entre las décadas del 70 y 80 del siglo pasado (Tabla 1).

Tabla 1. Evolución de la población en Soacha

\begin{tabular}{|c|c|}
\hline AÑO & POBLACIÓN \\
\hline 1964 & 11,435 \\
\hline 1973 & 23,054 \\
\hline 1985 & 103,800 \\
\hline 1990 & 169,071 \\
\hline 1993 & 183,997 \\
\hline 1999 & 278,000 \\
\hline 2003 & 363.019 \\
\hline 2005 & 402,007 \\
\hline
\end{tabular}

Fuente: elaboración propia con base en Montañez (1992), DANE (2003, 2010). 
En la década del 90 se expidieron dos documentos que se referían al ordenamiento territorial: el Acuerdo 91 de 1994 (Plan Integral de Desarrollo), y el Acuerdo 06 de 1995 (Plan de Ordenamiento Territorial Urbano). En dichos documentos, se muestra una clara tendencia a organizar lo urbano, no hay claras definiciones de las áreas de importancia ambiental y la parte rural queda relegada a un segundo plazo (Rozo, 2002). Un aspecto relevante fue el hecho de que el Acuerdo 06 no reconoció al humedal de Neuta, y se planteó la realización de un proyecto urbanístico sobre lo que ahora es el área protegida: "Nos dimos cuenta de que en el plano al humedal de Neuta lo habían borrado del mapa" (H. Medellín, com. pers., 19 de julio de 2013). Dado que el Acuerdo 06 no contaba con aprobación de la CAR, se inició un proceso contra la constructora y así se logró que el humedal fuera reconocido y sancionar penalmente a la urbanizadora (Carvajal, 1999).

Otro ejemplo de cómo la administración municipal se interesa en convertir espacios rurales y ambientales, en zonas industriales y urbanas, se encuentra en el Acuerdo 036 de 1997, que intentó convertir una zona netamente agrícola en zona industrial, contradiciendo incluso el Acuerdo 06 entonces vigente. El mencionado Acuerdo 036 fue declarado nulo por el Consejo de Estado en el año 2002, por contradecir normas superiores como la Ley 388 de 1997, la Ley 9 de 1989 y la propia Constitución (H. Medellín, com. pers., 19 de julio de 2013).

En 1999 se iniciaron los estudios para la expedición del actual Plan de Ordenamiento Territorial -POT-, el cual se adoptó por medio del Acuerdo 046 de 2000. Esta norma ha presentado los siguientes problemas: poca o nula participación ciudadana, no hay concertación del POT en la parte ambiental entre el municipio y la CAR, se encuentran dos versiones del Acuerdo 046 del 2000, lo que muestra "que detrás de él hay una pugna de poderes e intereses para que una determinada decisión se imponga" (Carvajal, 2011, p. 209).

Hacia el año 2004 aparece una nueva ola de poblamiento impulsada por el gobierno central, "los macroproyectos de vivienda". Este nuevo fenómeno urbanizador se volvió uno de los problemas más significativos para el territorio, ya que al no estar totalmente identificadas las áreas de importancia ambiental y al construirse sobre estas zonas, se ocasiona la pérdida de las mismas y del suelo fértil y de gran riqueza ambiental para el municipio. Así se presentan casos como la construcción de la urbanización "Parque Campestre" y 
otras viviendas de interés prioritario, en los terrenos que en los planes de manejo ambiental de los humedales Neuta y Tierra Blanca, debería ser un corredor ambiental.

Otro actor que interviene en el ordenamiento territorial sobre el territorio son las curadurías urbanas (Carvajal, 2011, p. 182), que permiten las construcciones y desarrollos urbanísticos sobre áreas que son objeto de protección o que requieren de usos diferentes a los autorizados. En el humedal Tierra Blanca se evidencia la acción de este actor, sobre todo en su costado sur, donde se encuentran industrias que tienen permiso de construcción, las cuales invaden incluso el cuerpo de agua.

Todo lo anterior refleja un desorden en la organización del territorio de Soacha, en donde a pesar de existir toda una normatividad para el ordenamiento territorial, este no responde a dicho marco legal sino a otros factores, tales como las presiones de intereses capitalistas y el desplazamiento forzado.

\section{Transformación y degradación del humedal Tierra Blanca}

La primera afectación al cuerpo de agua del humedal, se inició en la década del 60 por parte de la cur- tiembre Mendal Hermanos (Puentes \& Ruiz, 1988), que vertía sus aguas residuales al humedal. Años más tarde se ubicarían industrias como Alfagres, que continuarían con el vertimiento de aguas industriales, sin ningún tratamiento. En la misma época aparecen los primeros asentamientos urbanos, al dividirse la Granja Santa Ana en varias parcelaciones, que luego se convertirían en barrios y así continuaría la división predial y la ocupación del espacio por la urbanización de manera legal e ilegal.

En 1983 aparece el barrio Compartir, lo que marcó una nueva etapa en la ocupación del espacio en las cercanías del humedal Tierra Blanca y trajo consigo nuevos bienes y servicios al sector, dado que el barrio se convirtió en un centro de comercio importante y en una atracción para el asentamiento de población vulnerable y con menos poder de adquisición. De esta manera se crearon nuevas urbanizaciones de origen ilegal, que, a su vez, acrecentaron las presiones tanto en el aspecto ambiental como social y que repercutieron en el aumento de la degradación del humedal, que se manifestó en nuevos vertimientos de aguas residuales, invasión de la ronda de protección del humedal y el subsecuente fenómeno de inseguridad. En la actualidad, en el sector de Ducales, se han establecido varias familias que actúan como 
poseedores de los lotes que allí se encuentran. Según la misma comunidad, son unos 400 lotes y 310 casas (Personería Municipal de Soacha,
2010). La Figura 3 muestra la evolución del humedal desde el año 1981 y el fenómeno de ocupación del espacio en las cercanías del humedal.

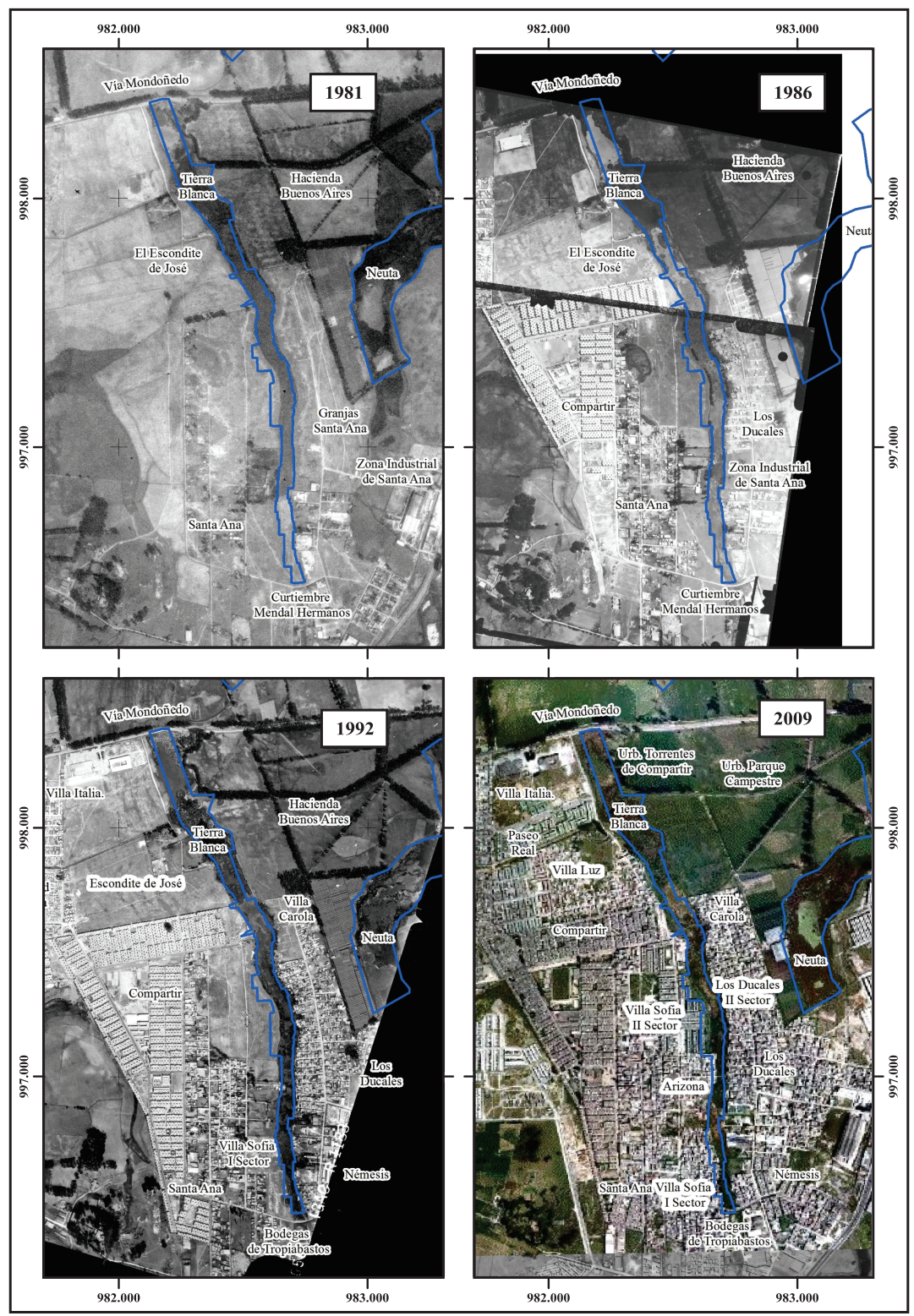

Figura 3. Análisis multitempóral de la transformación del humedal Tierra Blanca.

Fuentes: fotografías aéreas IGAC $(1981,1986,1992)$, Geoportal IGAC. 
En la década del 90 se ubicaron los barrios de origen legal Villa Sofía Uno y Dos, en la ronda del humedal. Muchas viviendas de estos sectores presentan problemas estructurales ocasionados por las condiciones naturales de los suelos que son arcillosos e indican un mal drenaje del agua (Salazar, 2005; Van der Hammen, 2008).
Hacia la década del 2000 se dispara el desplazamiento forzado por causa de la violencia, lo cual convirtió a Soacha en una de las ciudades más receptoras de este tipo de población; situación que a su vez agudizaría el fenómeno de la ocupación del espacio en los alrededores del humedal Tierra Blanca (Tabla 2).

Tabla 2. Recepción de población desplazada en Soacha por causa de la violencia (2000-2009).

\begin{tabular}{|c|c|}
\hline Año & $\begin{array}{c}\text { Población recibida en condición de } \\
\text { desplazamiento }\end{array}$ \\
\hline 2000 & 1.967 \\
\hline 2001 & 3.461 \\
\hline 2002 & 4.161 \\
\hline 2003 & 3.213 \\
\hline 2004 & 2.010 \\
\hline 2005 & 2.181 \\
\hline 2006 & 3.266 \\
\hline 2007 & 4.186 \\
\hline 2008 & 4.041 \\
\hline 2009 & 1.816 \\
\hline Total & 30.302 \\
\hline
\end{tabular}

Fuente: Unidad de Víctimas -SIPOD- (2009).

La suma de los factores mencionados ocasionó que alrededor del humedal de Tierra Blanca, convivan personas en condición de desplazamiento con personas de muy bajos recursos económicos, que nunca han sido víctimas de dicho flagelo, pero que tienen otra condición de vulnerabilidad. Según datos de la Personería Municipal (2010), dentro de la ronda del humedal existen en el momento alrededor de 320 predios, 120 de ellos en la zona del cuerpo de agua del humedal, la mayoría sin título de propiedad. Así mismo, el Plan de Manejo del humedal muestra que en el año 2006, en el área de influencia inmediata, se encontraban establecidas 23.676 personas (Salazar, 2006). 
Otro factor que afecta al humedal, es la construcción por parte de la comunidad de pasos peatonales que comunican los barrios de la parte oriental con la parte occidental, en donde se encuentran instalaciones como colegios y centros de salud (Aura Melo, com. pers. 20 de noviembre de 2011). Estos pasos, hechos con diferentes materiales, han originado la afectación al cuerpo de agua y la pérdida de flora y fauna nativa.

Aunque el humedal Tierra Blanca fue declarado reserva hídrica desde el año 2006, mediante el Acuerdo CAR No 033 del 7 de septiembre de ese año, y el Plan de Manejo Ambiental -PMA- fue aprobado por medio del Acuerdo 033 del 18 de diciembre de 2009, no se han adoptado medidas de conservación, protección, ni establecido controles y límites de las actividades, que permitan la recuperación, restauración y rehabilitación del humedal, así como el control de los diferentes usos que se deben realizar por parte de la CAR.

\section{Tierra Blanca frente a otros hu- medales}

Otros humedales de Soacha presentan estados similares al del humedal Tierra Blanca, con el agravante de que algunos como Potero Grande y Terreros prácticamente han desaparecido. Este aspecto contrasta con el estado de protección que tienen los humedales ubicados en la ciudad de Bogotá, ya que allí se han expedido varios acuerdos y resoluciones desde antes de la década del 90, lo que ha servido de ejemplo para la protección de los humedales en el ámbito nacional (SDA, 2006). En la actualidad, el Distrito Capital ha declarado catorce Parques Ecológicos Distritales de Humedal: Capellanía (18 ha), La Vaca (40 ha), Techo (3 ha), Tibanica (10 ha), El Burro 31 (ha), Córdoba (40 ha), Jaboque (147 ha) GuymaralTorca (73 ha), La Conejera (60 ha), Juan Amarillo o Tibabuyes (40 ha) Santa María del Lago (4 ha) (Pinilla, 2010) y el salitre (6.4 ha), (Humedales Bogota.com, 2013).

Los estudios limnológicos en los humedales de la Sabana de Bogotá muestran un alto grado de degradación de estos cuerpos de agua, algunos más críticos que otros (Pinilla, 2010). El humedal Tierra Blanca concentra un alto índice de de coliformes fecales a causa de la ausencia de sistemas de alcantarillados adecuados (Becerra, Puentes, Martínez \& Hernández, 2012). Así mismo, los humedales de la Sabana de Bogotá presentan características similares en cuanto a la flora y la fauna. Se destaca como el humedal Tierra Blanca contiene alta diversidad de artrópodos (Amat \& Blanco, 2003, p. 94) y se ha evidenciado la existencia de mamíferos poco convenciona- 
les, como la comadreja (Calvachi, 2003, p. 114).

El fenómeno de la urbanización también es similar en los humedales de la región. Así, por ejemplo, el humedal de Neuta comparte las mismas afectaciones que el humedal de Tierra Blanca en el sector que los conecta, y hacia el costado oriental donde se presentan urbanizaciones de origen legal pero que afectan directamente el cuerpo de agua (Pérez, Medellín, Quintero \& Mayorquin, 2002). Sin embargo, Neuta mantiene mejores condiciones que Tierra Blanca, gracias a que se encuentran organizaciones sociales que trabajan en pro de la conservación del humedal y han presionado acciones como la construcción del cerramiento y la presencia CAR que adicionalmente intenta cumplir con el PMA planteado para este humedal.

Por su parte, el humedal Tibanica o Potrero Grande presenta dos sectores, uno protegido en la ciudad de Bogotá y el otro en proceso de desaparición en el municipio de Soacha; lo que refleja las diferencias en el ordenamiento territorial entre Soacha y Bogotá. $\mathrm{Al}$ igual que en los anteriores, la urbanización es uno de los problemas más críticos en este humedal, puesto que ocasionó la fragmentación del área original, especialmente por las invasiones ilegales que se realizaron en el sector (Perdomo, 2010). En el lado de Potrero Grande no ha sido reconocido ni por la CAR ni por la Alcaldía de Soacha. Allí se realiza el macroproyecto Ciudad Verde, lo que tiende a que este humedal desaparezca dentro de muy poco. El costado protegido se encuentra en mejor estado; sin embargo es afectado por vertimientos de aguas residuales, industriales y domésticas al canal Tibanica, principal fuente de abastecimiento del humedal (Perdomo, 2010).

Todo lo anterior muestra la grave condición en la que se encuentran los humedales de Soacha, situación que tampoco es del todo ajena a la ciudad de Bogotá, en donde aunque exista un marco normativo más amplio que los reconoce, también se ven graves daños. Ejemplo de esto es el humedal de Jaboque, ubicado en la localidad de Engativá del Distrito Capital, que también ha sido afectado de forma similar a los anteriores por las presiones urbanísticas e industriales, coincidiendo incluso en las épocas en que se incrementó la población. Su área se ha visto reducida desde la construcción del aeropuerto El Dorado y la calle 26, y los procesos de urbanización acelerados (Rangel \& Orjuela, 2005).

\section{Futuro del humedal Tierra Blanca}

El estado actual del humedal no permite reversar los efectos y con- 
secuencias ya creadas, pero es indispensable recuperar el área y devolverle la importancia ambiental, cultural e histórica que ostentaba hace algunos años, y para ello es necesario que se realicen diferentes acciones tanto a nivel local, como regional y nacional, que necesariamente comprenden la coordinación de todos los actores involucrados con el humedal. Tal vez la acción más importante por llevar a cabo, es la apropiación del espacio por parte de la comunidad, la cual se logrará si existe un cambio en la percepción que tienen los habitantes del sector sobre su entorno, se reconstruye la memoria histórica del territorio y del humedal, y adicionalmente se ejecutan las acciones pertinentes por parte de los entes encargados del ordenamiento territorial del municipio.

Para lograr el cambio en la percepción comunitaria, es necesario modificar condiciones que se presentan a diario, como: la inseguridad, la imagen del humedal como zona de acumulación de residuos sólidos y la limpieza de este. En los humedales de Bogotá se han abordado experiencias trabajando con la percepción que tienen las personas sobre su entorno (Yori, 1998), y asumen el concepto de topofilia ${ }^{2}$ adoptado por Tuan (1977), lo cual sería herramienta útil

2 Según Tuan (1997), es el afecto por los lugares. para contrastar los efectos negativos sobre el humedal Tierra Blanca. Adicionalmente es necesario establecer estrategias para el conocimiento del humedal y sus problemas, fortalecer los procesos en marcha y divulgar las acciones emprendidas y por emprender.

Es urgente realizar los trabajos de alcantarillado, para reducir los actuales vertimientos de aguas residuales al cuerpo de agua, que generan malos olores. En ese orden de ideas, es necesario trabajar desde la ingeniería para mejorar la calidad del agua y recuperar el espejo de agua perdido. Además aportaría al mejoramiento del paisaje, pues se reducirían los olores e imágenes desagradables del humedal. La vulnerabilidad respecto de posibles inundaciones hacia el futuro por el desbordamiento de las aguas del humedal, hace indispensable efectuar obras de regulación hídrica que recuperen la capacidad del humedal respecto del control de inundaciones.

Es necesario que las organizaciones sociales que se encuentran trabajando en esta área coordinen sus esfuerzos y se enfoquen en unas metas conjuntas. En ese sentido es importante que los líderes comunitarios no sean infiltrados por intereses ajenos a las comunidades y al bienestar del humedal, pues es este uno de los problemas más críticos, ya que 
la mayoría de líderes actúa conforme a lo que disponen otros actores. $\mathrm{Al}$ fortalecer estos grupos se pueden realizar ejercicios como las acciones populares, que han resultado efectivas en lugares como el humedal de Neuta, tal como lo narra la comunidad: "nosotros hemos hecho tres acciones populares y las tres las hemos ganado y hemos renunciado al incentivo. Porque el objetivo no es convertirnos en caza recompensas" (H. Medellín, com. Per., 19 de julio de 2013).

Estas formas de actuar de las organizaciones generan una manera de ejercer el poder popular dado por la Constitución Política y afianzan la participación de la comunidad en las decisiones que se toman sobre el territorio, lo que indica que "hay tres formas de hacer gobierno 1. Por la vía electoral 2. Por las armas (pero está desvalorizada, descontextualizada) 3. A través de la movilización popular obligar que el Estado funcione o funcione (sic)" ( $\mathrm{H}$. Medellín, com. pers., 19 de julio de 2013). Así mismo, es necesario recobrar ejercicios de redes sociales, como el logrado con la Red de Humedales, a la que perteneció el Cabildo Verde de Soacha, que tuvo éxitos sobre todo en la interposición de acciones populares en los humedales de La Conejera y Tibabuyes.

Se debe hacer un esfuerzo impor- tante para que la comunidad conozca el territorio de Soacha, no solo en la parte urbana sino en la parte rural, lo cual da una idea de cómo era el territorio en el pasado y ayuda a entender la importancia de las áreas ambientalmente importantes. De igual forma se deben incorporar las estrategias educativas como los Proyectos Ambientales Escolares, los Comités Técnicos Interinstitucionales de Educación Ambiental y los Proyectos Ambientales Ciudadanos de Educación Ambiental y los demás establecidos en la Ley 115 de 1994 o Ley General de Educación (Mora, 2012).

Asociados a esto, hay instrumentos como la CEPAL (Hesselink et al; 2007), que se desarrolla a partir del artículo 13 del Convenio de la Biodiversidad y abarca temas como la comunicación, la educación, la conciencia pública, la participación, los instrumentos de política y acción e investigación para la acción. Estas estrategias se enmarcan en la planificación y ordenación del territorio, que como se ha mencionado es un punto importante en la recuperación del humedal.

Se debe hacer un ordenamiento territorial que involucre de manera directa a las comunidades, tenga en cuenta los conceptos sobre desarrollo sostenible, realce la imagen corporativa del municipio y de la Comuna Uno, 
y le dé una verdadera importancia a estos sectores olvidados. De igual manera se debe reconsiderar la política de vivienda en Soacha, ya que esta afecta tanto a las áreas de importancia ambiental como la calidad de vida de los habitantes del municipio, que ven como, a medida que crece la población, los servicios básicos son cada vez menos eficientes y más indignos, y no aseguran la prestación de los mismos (A. Melo, com. pers. 20 de noviembre de 2011).

Dado que el humedal Tierra Blanca, en algunas zonas, no podrá recuperarse, se deben llevar a cabo medidas de compensación. En ese sentido se debería reconocer el relicto de humedal que no ha sido reconocido en el POT, ni por la CAR y que fue parte de Tierra Blanca antes de la construcción de la vía SoachaMondoñedo, pues este tiene mejores condiciones que la parte declarada como Reserva Hídrica. En este sitio se puede recobrar el cuerpo de agua y lograr condiciones que se asemejen a sus características iniciales $(\mathrm{H}$. Medellín, com. pers., 19 de julio de 2013).

Igualmente se deben comprar los predios ubicados dentro del humedal y en la zona de ronda, y reubicar en condiciones de vivienda digna a las personas que allí viven, para lo cual deberían usarse las viviendas que se construyen en varios de los macro- proyectos. Sin embargo, la administración municipal no ha considerado esta alternativa como solución al problema de vivienda dentro del humedal (A. Melo, com. pers. 20 de noviembre de 2011). Para el costado sur es necesario pensar en otras opciones como la construcción de un pequeño canal que conecte con la parte central y sur, recobrar la parte que fue invadida por la curtiembre Mendal Hermanos sobre lo que hoy se encuentran las bodegas de Tropiabastos (H. Medellín, com. pers., 19 de julio de 2013).

No obstante, para lograr todos los cambios mencionados, se debe replantear la labor de instituciones como la CAR, que no ha intervenido de forma contundente en el humedal de Tierra Blanca, pues es una entidad politizada que actúa en pro de los intereses del político de turno $(\mathrm{H}$. Medellín, com. pers., 19 de julio de 2013; A. Melo, com. pers. 20 de noviembre de 2011). Todos estos cambios deben conducir a una gobernanza ambiental, que se entiende como el "proceso colectivo y democrático de toma de decisiones que involucra actores estatales, actores privados y una participación amplia de actores tradicionalmente excluidos" (Hernández, Flores \& Naranjo, 2011, p. 13). Esta es una opción que lograría rescatar del caos al humedal Tierra Blanca. 


\section{Conclusiones}

El ordenamiento territorial en Soacha ha sido permeado por intereses que no están acordes con las necesidades territoriales del municipio y ha llevado a que se deterioren áreas de importancia ambiental como el humedal Tierra Blanca, donde las acciones de los diferentes entes encargados lo han llevado a un estado de deterioro irreversible. Es así como los procesos de urbanización e industrialización, se vuelven los principales problemas del humedal que lo han conducido a una situación de posible extinción.

El valor del suelo y la falta de espacios en la ciudad de Bogotá para la construcción de vivienda, hicieron que la mayoría de las personas que allí habitan, sean de estratos bajos y que posean ciertas condiciones de vulnerabilidad (desplazamiento forzado, pobreza, discriminación). De esta forma, la urbanización en las cercanías del humedal se presenta en dos sentidos: construcciones ilegales en el interior del área protegida (incluso dentro del cuerpo de agua) y la construcción de vivienda legal, pero en condiciones indignas. Las entidades encargadas de la protección y el cuidado del humedal, han actuado de manera tardía sobre el humedal, y han ocasionado que otras dinámicas actúen sobre el territorio y el área protegida. Esto se evidencia en el hecho de que el Plan de Acción estipulado por PMA no se ejecute en ninguno de sus aspectos y, de esta forma, todas las normas para la protección del humedal se queden solamente en el papel y se vuelvan instrumentos insuficientes para la recuperación y cuidado del humedal.

Se hace necesario replantear el actuar de las entidades públicas como la CAR y la administración municipal, que solo realizan proselitismo político con el humedal y que en realidad no ejecutan las acciones que por ley les compete. Es, por lo tanto, de suma importancia cambiar los estereotipos que se han establecido hacia el ordenamiento del territorio y realizar una ordenación alternativa que involucre de manera directa a todos los actores (públicos, privados y comunidad) y cambie la percepción que tiene la comunidad frente al municipio y la Comuna Uno, como alternativa a la recuperación de espacios como el humedal Tierra Blanca. 


\section{Referencias}

Amat, G. \& Blanco, E. (2003). Artropofauna de los humedales de la Sabana de Bogotá. En Empresa de Acueducto y Alcantarillado de Bogotá. Los humedales de Bogotá y la Sabana. Volumen 1. Conservación Internacional. Bogotá: EAAB.

Becerra, L., Puentes, V., Martínez, J. \& Hernández, J. (2012). ADRA para la identificación de las bacterias coliformes Citrobacter sedlakii y Citrobacter gilleni, del humedal "Laguna de Tierra Blanca” Soacha, Cundinamarca. Revista Mutis, 2(2), 76-88.

Calvachi, Z. B. (2003). La fauna en los humedales de Bogotá y la Sabana. En Empresa de Acueducto y Alcantarillado de Bogotá. Los Humedales de Bogotá y la Sabana. Vol. 1, Conservación Internacional. Bogotá:EAAB

Carvajal, M. (1999, 13 de sep.). Lío por casas al lado de humedal. El Tiempo Bogotá. Recuperado de http://www.eltiempo.com/archivo/ cronologico?pagina $=39 \& \mathrm{a}=1999 \&$ orden $=$ reciente $\& \mathrm{~m}=09 \& \mathrm{~d}=13$

Carvajal, N. I. (2011). La dinámica del ordenamiento territorial en Colombia: contraste de dinámicas urbano-rurales en la región metropolitana de Bogotá. Canadá: Universidad de Montreal.

Cifuentes, A. (2010). El agua en la historia: devenir del agua en las civilizaciones. En El Abedul. Recuperado de: http://www.elabedul.net/Documentos/Temas/Otros/El_agua. pdf

Correa, F. (2004). El sol del poder: simbología y política entre los muiscas del norte de los Andes. Colección Sede. Bogotá: Universidad Nacional de Colombia.

Delgado, J. D. (2010). La construcción social del paisaje de la Sabana de Bogotá 1880-1890. Bogotá: Universidad Nacional de Colombia.

Departamento Nacional de Estadística -DANE- (2003). Censo experimental de población y vivienda del municipio de Soacha. Informe final. Bogotá: DANE Dirección de Censos y Demografía.

Departamento Nacional de Estadística -DANE- (2010). Proyecciones nacionales y departamentales de población 2005-2010. Bogotá: Centro Andino de Altos Estudios CANDANE.

Espinosa, M. (2009). Perspectiva de la geografía crítica en el estudio de la ciudad colombiana contemporánea. En J. W. Montoya (ed.). Lecturas en teorías de la geografía. Bogotá: Universidad Nacional de Colombia, Facultad de Ciencias Humanas, Departamento de Geografía.

Harvey, D. (2008). El derecho a la ciudad. Revista Rebelión. Recuperado de http://www. rebelion.org/noticia.php?id $=73859$.

Hernández, A., Flórez, J. \& Naranjo, M. (2010). Gobernanza ambiental, trayectoria institucional y organizaciones sociales ambientales en Bogotá: 1991 -2010. Bogotá: CIDER, Universidad de los Andes, Fundación Carolina. 
Hesselink, F., Goldstein, W., Van Kempen, P. P., Garnett, T. \& Dela, J. (2007). La comunicación, educación y conciencia pública. Una caja de herramientas para personas que coordinan las estrategias y planes de acción nacionales sobre diversidad biológica. Montreal. Secretaría para el Convenio sobre la Diversidad Biológica. España: UICN, Universidad Autónoma de Madrid, Comisión de Educación y Comunicación, Ministerio de Medio Ambiente y de Medio Rural y Marino de España.

HumedalesBogotá.com (2013). Humedal El Salitre. Recuperado de http://humedalesbogota. com/humedales-bogota

Jiménez, L. C. (2009). Espacialidad urbana de propietarios e inquilinos en sectores populares. El caso de Bogotá, 1938-2000. En M. Castillo (ed.). Procesos urbanos informales y territorio. Ensayos en torno a la construcción de sociedad, territorio y ciudad. Bogotá: Universidad Nacional de Colombia, grupo de investigación Procesos urbanos en hábitat, vivienda e informalidad, Facultad de Artes, Maestría en Hábitat.

Lozada, H. (2000). Soacha: Plan de ordenamiento territorial. Boletín de la Sociedad Geográfica de Colombia, 44(131). Recuperado de http://www.sogeocol.edu.co/ documentos/soacha_pot.pdf.

Moncayo, E. (2004). Las políticas regionales en Colombia. En Nuevos enfoques del desarrollo territorial: Colombia en una perspectiva latinoamericana. CEPAL, UNDP.

Montañez, G. (1992). ¿Hacia dónde va la Sabana de Bogotá? Bogotá: Universidad Nacional de Colombia, Centro de Estudios Sociales -CES-, Servicio Nacional de Aprendizaje SENA.

Mora, W. M. (2012). PRAES aplicados a la conservación de los humedales. Presentación curso Biodiversidad y conservación de los humedales de Colombia. Bogotá: Asociación Ecovida, Fundación Natural Planet y el Colectivo humedalesbogota.com.

Moreno, O. E. (2004). A propósito de los procesos de conurbación en el sur de la metrópoli bogotana. Revista Bitácora.

Novoa, E. A. (2010). La metamorfosis de la cuestión espacial en Colombia. Bogotá: Universidad Nacional de Colombia, Facultad de Derecho, Ciencias Políticas y Sociales, Instituto Unidad de Investigaciones Jurídico Sociales Gerardo Molina -UNIJUS-.

Perdomo, M. L. (2010). Diseño participativo de un modelo de seguimiento, monitoreo y control social a los humedales urbanos de Bogotá, D.C. Estudio de caso humedal Tibanica. Bogotá: Universidad Nacional de Colombia, Instituto de Estudios Ambientales.

Pérez, C., Medellín, H., Quintero C. \& Mayorquin, D. L. (2002). Humedales lagunas de Neuta y Tierra Blanca patrimonio ecológico de Soacha para el país y las futuras generaciones. Soacha: Cabildo Verde.

Pérez, A. (2000). La estructura ecológica principal de la Sabana de Bogotá. Bogotá: Sociedad Geográfica de Colombia, Academia de Ciencias Geográficas. Recuperado de http:// www.sogeocol.edu.co/documentos/est_eco.pdf.

Personería Municipal de Soacha. (2010). Actas de reunión y otros. Soacha, Cundinamarca. 
Pinilla, G. (2010). An index of limnological conditions for urban wetlands of Bogota' city, Colombia. In Ecological Indicators. Retrieved from www.elsevier.com/locate/ecolind.

Preciado, J. (2005). Historia ambiental de Bogotá en el siglo XX: elementos históricos en la formulación del medio ambiente urbano. Bogotá: Universidad Distrital.

Puentes, M. C. \& Ruiz, L. M. (1988). Estudio de la contaminación en la laguna de Tierra Blanca, municipio de Soacha, departamento de Cundinamarca. Bogotá: Universidad Social Católica de la Salle.

Rangel, J. \& Orjuela, M. (2005). Humedales de la localidad de Engativa: el Humedal de Jaboque. Bogotá Instituto de Ciencias Naturales, Universidad Nacional de Colombia.

Rozo, J. (2001). Usos del espacio como sistema y procesos de formación del orden territorial en Soacha. Bogotá: Universidad Nacional de Colombia, Facultad de Ciencias Humanas, Departamento de Geografía.

Salazar, L. (2006). Revisión y ajuste de los planes de manejo ambiental de los humedales de Neuta, Tierra Blanca, laguna de La Herrera y Humedal el Yulo. Soacha, Cundinamarca: Corporación Autónoma Regional Cundinamarca.

Santos, M. (1996). De la totalidad al lugar. M. L. Silveira (trad.). Barcelona: Oikos-Tau.

Secretaría Distrital de Ambiente de Bogotá -SDA- (2000). Historia de los humedales de Bogotá con énfasis en cinco de ellos. Bogotá: Alcaldía Mayor de Bogotá D.C.

Secretaría Distrital de Ambiente de Bogotá -SDA- (2006). Políticas de humedales del distrito capital. Bogotá: Alcaldía Mayor de Bogotá D.C.

Soja, E. W. (2010). Seeking the spatial justice. Minnesota, USA: University of Minnesota Press.

Tuan, Y. F. (1974). Topophilia. A Study of environmental perception, attitudes, and values. Englewood Cliffs, New Jersey: Prentice-Hall Inc.

Unidad para la Atención y Reparación Integral a las Víctimas. (2009). Sistema de Información para la Población Desplazada (SIPOD). Bogotá: Acción Social.

Van der Hammen, T., Stiles, F. G., Rosselli, L., Chisacá, M. L., Camargo, G., Guillot, G., Useche, Y. \& Rivera, D. (2008). Protocolo de recuperación y rehabilitación ecológica de humedales en centros urbanos. Bogotá: Alcaldía Mayor de Bogotá D.C., Secretaría Distrital de Ambiente.

Yory, C. M. (1998). La topofilia: una estrategia para hacer ciudad desde sus habitantes. Bogotá: s.n. 
Recepción: 17 de agosto de 2013

Evaluación: 19 de septiembre de 2013

Aprobación: 04 de diciembre de 2013 